\title{
Amaranto en México: viejas estrategias productivas y nuevos consumidores
}

A partir de los resultados de un estudio de caso en el pueblo de Huazulco, Morelos (Centro de México), sobre talleres artesanales y pequeńas empresas que se dedican a producir dulces tradicionales de amaranto, se reflexiona sobre el actual desarrollo de esta cadena agroalimentaria. El amaranto es un producto ancestral que contiene un alto valor nutritivo, que en la época prehispánica tuvo amplio consumo y valor ritual, pero tras la conquista se fue limitando y mantuvo por siglos una reducida presencia. Sin embargo, en las últimas décadas la superficie sembrada en el país se cuadruplicó y aumentó su demanda nacional y para exportación. Este apogeo se relaciona con cambios en los patrones alimenticios y la segmentación del mercado agroalimentario global. Se discute sobre el posible impacto y eventual beneficio del auge en la producción de amaranto y diferenciación de la demanda para campesinos, agroindustrias de arraigo local y comunidades rurales como Huazulco en México.

Palabras Clave: producción; consumo; cadenas agroalimentarias; antropología de la alimentación.

\section{Amaranth in Mexico: old productive strategies and new consumers}

\begin{abstract}
Based on the results of a case study in the town of Huazulco, Morelos (Central Mexico), on artisan workshops and small business that are dedicated to produce traditional amaranth sweets, we reflect on the current development of this agro-food chain. Amaranth is an ancestral product that contains a high nutritional value, which in pre-Hispanic times had a high consumption and ritual value, but after the conquest it was limited and keep for centuries a reduced presence. However, in the last decades the area planted with amaranth in the country quadrupled and increased its national and exportation demands. This apogee is related to changes in food patterns and the segmentation of the global agro-food market. The potential impact and benefit of the boom in amaranth production and demand differentiation for peasants, local rooting agro industries and rural communities such as Huazulco in Mexico is discussed.
\end{abstract}

KEY WORDS: production; consumption; agro-food chains; food anthropology.

\footnotetext{
* Doctora en Antropología, Centro de Investigación en Ciencias Sociales y Estudios Regionales, Universidad Autónoma del Estado de Morelos. ** Maestra en Ciencias Agropecuarias y Desarrollo Rural, Universidad Autónoma del Estado de Morelos.
} 


\section{Introducción}

«iAlegría!» «iLleve su Alegría!» «TTres-por-diez!» se escucha el pregón de un vendedor ambulante al ofrecer a los transeúntes esa popular golosina de precio accesible. Alegría es el nombre del dulce tradicional de amaranto en México - conocido en tierras peruanas como kiwicha-, que consiste en barras rectangulares formadas con miel de abeja y piloncillo (chancaca), comúnmente adornadas con pasas de uva o nuez.

Llama la atención que, además de mantenerse éste arraigado manjar elaborado por talleres artesanales y pequeñas empresas, hay una creciente demanda de nuevas y variadas presentaciones, acompańado de la toma de conciencia y divulgación a nivel mundial de los altos valores nutritivos y saludables del amaranto, ahora utilizado como materia prima por agroindustrias de diferente tamaño, cuyos productos que se ofertan en supermercados y tiendas naturistas con vistosas etiquetas, y a precios notoriamente superiores.

Modernos canales han difundido la información sobre las bondades del amaranto para una dieta sana, así como fuente alternativa de calcio y otros compuestos alimenticios. En pocos años ha engrosado el concierto de pequeños granos -como quinua, chía, linaza, mijo y otros-antes relativamente desconocidos en el menú agroalimentario internacional y que ahora pareciera no pueden faltar en una cocina y una despensa sofisticada surtida de superalimentos.

Influenciados por este auge en la demanda, la siembra de amaranto en México se cuadruplicó desde fines del siglo pasado, manteniendo hoy día una superficie superior a cinco mil hectáreas, con un volumen de seis mil quinientas toneladas (Navarrete, 2017). El consumo interno de amaranto ha incrementado y también su exportación. Campesinos, talleres artesanales, empresas familiares y otras, crearon expectativas del beneficio económico que acompañaría este aumento, siendo conjuntamente considerado por organismos de gobierno como una vía o catalizador del desarrollo local.

Pero especialistas en fitotecnia diagnosticaron que estas posibilidades dependen de cambios significativos en la forma de cultivar el amaranto y en otros eslabones, pues consideran que esta cadena de valor está poco integrada, que no existen vínculos horizontales a nivel de los productores y tiene una débil promoción en mercados internacionales, entre otros obstáculos que limitan su competitividad (Ayala et al., 2016).
En contraste a estos juicios, una investigación etnográfica realizada recientemente en Morelos por una de las autoras del presente artículo, sobre los artesanos «amaranteros» y sus talleres (Navarrete, 2017) ${ }^{1}$, brinda una imagen un tanto diferente, al encontrar importantes lazos horizontales y relaciones de intercambio entre productores, proveedores, intermediarios comerciales $\mathrm{y}$ consumidores, que en conjunto permiten abastecer diferentes canales mercantiles regionales y nacionales. Sus hallazgos, si bien acotados a las agroindustrias rurales que elaboran productos derivados de amaranto en un pueblo, Huazulco, matizan aquellas afirmaciones y sugieren que los artesanos tienen estrategias alternativas, que escapan a modelos de tinte empresarial. Su participación en los diferentes canales mercantiles en la actualidad, empero, los confronta a diferentes paradojas y dilemas para su reproducción social y cultural.

El principal objetivo de este artículo es reflexionar, desde un caso particular, en el impacto y posible beneficio del auge en la producción de amaranto y diferenciación de la demanda para campesinos y agroindustrias de arraigo local, así como comunidades rurales involucradas en México.

En el primer apartado se mencionan antecedentes sobre el amaranto y su cadena agroalimentaria, así como los principales productores en México. En el segundo apartado, se presenta una breve síntesis de los resultados de la investigación realizada en Huazulco, Morelos, centrada en las agroindustrias que elaboran los dulces tradicionales; así mismo, se explora cuán importante es el comercio convencional y el papel de los nuevos mercados para estos talleres y empresas familiares. Para comprender las tendencias que subyacen al creciente boom de productos artesanales en normas de consumo globales, en tercer lugar, se hace alusión a los consumos simbólicos del amaranto y su importancia social como portador de mensajes e imaginarios para ciertos nichos de mercado. Finalmente, a partir de este estudio de caso, a manera de conclusión se reflexiona sobre las ventajas, las desventajas y los desafíos que representan

$1 \quad$ El presente artículo se basa en la investigación de Elizabeth Navarrete Galindo, La ruta del Huaubtli (Amaranto) en Morelos, sustentada en el examen profesional de Maestría en Ciencias Agropecuarias y Desarrollo Rural, de la Universidad Autónoma del Estado de Morelos, el 26 de junio de 2017. Salvo aclaración contraria, la información que figura en este documento se basa en los resultados de esta investigación que sistematiza diversas fuentes documentales, además de amplia evidencia empírica de su estudio de caso. Cabe aclarar que «Huauhtli» es el nombre original en náhuatl, empleado en Mesoamérica en periodo prehispánico y que se conserva en comunidades indígenas hablantes. 
los cambiantes hábitos alimenticios asociados al amaranto, para pequeños productores y artesanos de Huazulco.

\section{Antecedentes del amaranto e indicadores actuales}

El género amaranto cuenta con 50 o 60 especies, distribuidas en regiones templadas y tropicales de América, siendo las especies mexicanas más conocidas las $A$. hypochondriacus, $A$. cruentus y $A$. hibridus, en tanto en la zona andina es de mayor renombre la $A$. caudatus.

Estudios recientes indican que los restos botánicos arqueológicos de amaranto (Amaranthus spp), de mayor antigüedad en Mesoamérica, datan de hace unos 9000 años. Diferentes excavaciones identifican su presencia en diversos sitios de la Cuenca de México y documentos etnohistóricos registran que fue parte de la dieta de las poblaciones prehispánicas.

Se sabe que entonces tenía gran importancia alimentaria y también que era un poderoso elemento simbólico en la cosmovisión mesoamericana, valor que aún conserva en algunas comunidades indígenas.

Las culturas mesoamericanas lo llamaban huaubtli, nombre en náhuatl que puede traducirse como «la partícula más pequeña capaz de dar vida». El huaubtli o amaranto es mencionado en el manuscrito de Fray Bernardino de Sahagún —conocido como Códice Florentino-, el cual es una invaluable fuente de información sobre la vida cotidiana de los indígenas en México del siglo xvı. ${ }^{2}$ Existen diversas evidencias de su importancia ceremonial, como alimento ritual y ofrenda a las deidades, para agradecer y pedir el sustento, el agua y la vida. Era usado para elaborar un producto llamado tzoalli, el cual consistía en una masa preparada con harina de amaranto tostado, a veces mezclada con harina de maíz, y miel negra de abeja o maguey, la cual servía para moldear diferentes figuras antropomorfas, zoomorfas (aves, serpientes y otros animales), fitomorfas y otras.

Algunos autores refieren a que, tras la invasión europea, se prohibió su cultivo por asociarlo a creencias

2 En dicho documento se destaca que el huaubtli era de consumo habitual en Tenochtitlan y formaba parte del tributo de 17 de las provincias conquistadas por los mexicas; de acuerdo a algunos autores, se le consideraba un grano alternativo en los casos en los que se tenía una mala cosecha del maíz, pues el huauhtli era una planta más resistente a cambios climáticos. "paganas", reduciendo considerablemente su siembra. ${ }^{3}$ Por ello, cultivo y consumo de amaranto se redujeron drásticamente, aunque se conservó sobre todo en el Altiplano Central de México, en unárea en que en la actualidad se concentra su producción, la cual corresponde a pueblos que se ubican alrededor de los volcanes Popocatépetl e Iztaccíhuatl (Mapa 1).

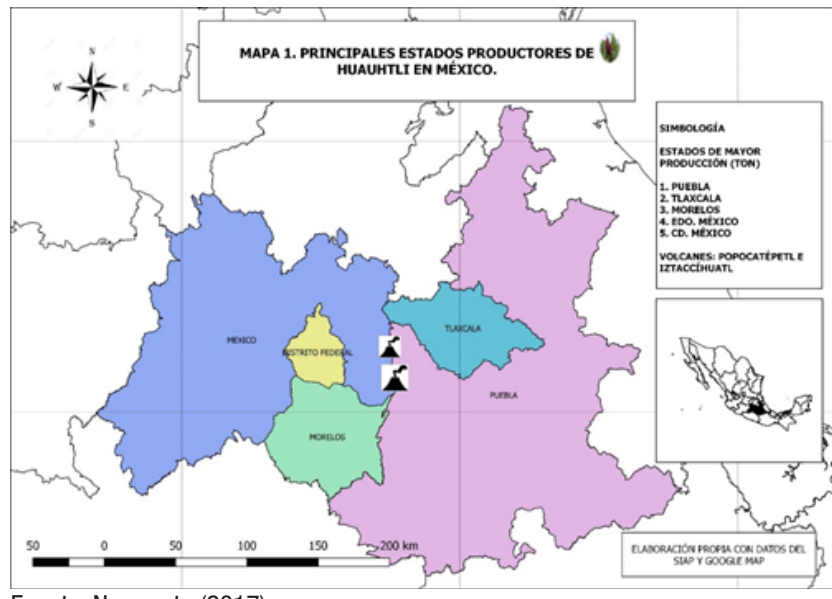

Fuente: Navarrete (2017)

En estos lugares, a lo largo de los siglos varias comunidades rurales se fueron especializando en la tradición artesanal de elaboración de dulces de amaranto (Alegría), de cacahuate o maní (palanquetas) ${ }^{4}$, pepitas de calabaza y otras semillas e ingredientes, de acuerdo a las diferentes gastronomías regionales. De tal manera, continuó siendo un cultivo relativamente modesto, desarrollado por campesinos en pequeñas extensiones y transformado por talleres artesanales o industrias caseras, para un extendido consumo popular como golosina en pueblos y ciudades, si bien como se mencionó ha tenido un persistente uso ceremonial en algunas comunidades indígenas. ${ }^{5}$

3 Con frecuencia se menciona que los conquistadores castigaban cruelmente a los nativos que sembraban amaranto cortándoles las manos, si bien no se han encontrado evidencias documentales al respecto.

4 La palanqueta es una barra de maní pelado y sin cáscara, mezclado con jarabe de chancaca, su textura es crujiente y su nombre deriva de la voz papaquili, que significa «feliz» o "alegre», pues en sus primeras versiones prehispánicas se ofrecía en la Feria del Maíz (Papaquilizilhuitl). Así pues, este dulce también es de origen prehispánico, originalmente hecho en base a maíz tostado y molido, mezclado con miel de abeja, pero tras la conquista sus ingredientes fueron reemplazados: la miel por jarabe de caña y el maíz por cacahuate u otras semillas (www.gob.mx/ sagarpa/artículos/palanqueta-una-alegre-delicia-envuelta-de-tradicion. Consultado 05/07/2017).

5 En comunidades nahuas de la Montaña de Guerrero se elaboran figuras de tzoalli, sobre todo como parte de la petición de lluvias que se realiza el 25 de abril, adaptándose al santoral católico, en que se celebra a 
Sin embargo, desde los años setenta diferentes estudios promocionaron su alto valor nutrimental, siendo mundialmente conocido el estudio agronómico del Rodale Research Center de Estados Unidos en 1975, a través de su revista Organic Gardening and Farming, que no solo dio amplia difusión a sus bondades alimenticias y su gran capacidad de adaptación edafológica, sino que además incluyó un sobre de semillas, invitando a los lectores a sembrarlas e informar de sus resultados (Vargas y Del Valle, 2016). No queda claro si este evento fue clave en su exitosa diáspora, lo cierto es que siendo reconocido su origen mesoamericano y andino a nivel internacional, su cultivo se fue expandiendo en otros continentes. ${ }^{6}$

Sucesivas investigaciones destacaron su alto contenido nutricio para la alimentación humana, debido a que es rico en proteínas, carbohidratos y grasas, convirtiéndolo en un alimento energético por excelencia, pero también se han descubierto múltiples aplicaciones tecnológicas, por ejemplo, para la industria farmacéutica, ya que tiene propiedades nutracéuticas e incluso auxiliar en la prevención de enfermedades como osteoporosis, colesterol en la sangre, así como el poder antioxidante que presenta gracias al tocoferol (vitamina E).

En México las estadísticas agropecuarias oficiales registran el cultivo de amaranto a partir de 1982, lo que no significa que no se sembrara antes. En aquel ańo, se reporta que contaba con 410 hectáreas en dos estados, ${ }^{7}$ las cuales producían 222 toneladas. En proporción casi geométrica este volumen fue creciendo en más lugares y ya en 1995, llegaba a 989 toneladas en una extensión de 817 hectáreas, lo cual muestra también que los rendimientos se habían duplicado, reflejando mayor interés en desarrollar variedades mejoradas. El despegue definitivo ocurre en el siguiente quinquenio, cuando la superficie supera las tres mil hectáreas y un volumen de 4,240 toneladas en el año 2000. Sin embargo, estos indicadores tendrán un comportamiento errático el siguiente decenio y hasta 2014, nuevamente hay un aumento notable y el siguiente ciclo llegó a su mayor extensión, con 6,485 hectáreas y un volumen

San Marcos, asociado en la región a los ritos propiciatorios para la agricultura.

6 Diferentes variedades de amaranto se cultivan en México, Perú, Ecuador, Estados Unidos, India, China entre otros. En China es utilizado principalmente como alimento para ganado.

7 En México la división administrativa de estados (o entidades federativas) es equivalente a Provincia en Perú. Cada estado se divide a su vez en Municipios. de producción de 8,511 toneladas. Posteriormente, en 2016, hay un descenso de casi tres mil hectáreas, disminución que prácticamente se debe a la reducción del cultivo en el Estado de Tlaxcala. ${ }^{8}$

$\mathrm{Al}$ parecer, este auge del consumo nacional se debe a la ampliación, diversificación y modernización de productos y derivados del amaranto (harinas, pan, galletas, granolas y frituras, entre otros); aunque también se ha incorporado a las exportaciones agrícolas. De acuerdo con el Sistema de Seguimiento Oportuno de Comercio Exterior, México exporta amaranto principalmente a países como Italia (42\%), Estados Unidos (37\%), Colombia (12\%) y en menor proporción a Canadá y Cuba. ${ }^{9}$

En Morelos, el cultivo de amaranto está concentrado en el municipio nororiental de Temoac, cercano al volcán Popocatepetlya mencionado, donde se localizan alrededor de 300 hectáreas de sembradío. Cabe hacer notar que Morelos es vecino de Ciudad de México (antes llamado Distrito Federal), desde siempre el mayor mercado nacional de consumidores por el tamańo de su población. ${ }^{10}$

En la carretera que lleva a este lugar un arco anuncia la leyenda "Temoac Tierra de Amaranto». Prácticamente la totalidad de su siembra se encuentra en los pueblos de Huazulco y Amilcingo. A su vez, en estas comunidades se ubican los talleres de dulces tradicionales y las agroindustrias transformadoras de amaranto. Temoac cuenta con 14,641 habitantes, 26\% de los cuales viven en Huazulco y $22 \%$ en Amilcingo.

Los productores son campesinos minifundistas y sus tierras de labor tienen en promedio 2.7 hectáreas, de las cuales solo una porción se dedica a la siembra de este pequeño grano, en tierras de temporal. Actualmente, autoridades locales registraron 300 campesinos que solían cultivar amaranto, pero cada año la participación de los productores y el área a sembrar es variada. En Temoac, como en diversas comunidades del campo morelense, la gran mayoría de los productores cultivan

$8 \quad$ En las últimas décadas el cultivo se concentra principalmente en Puebla y Tlaxcala, en menor medida en Morelos, Estado de México, Ciudad de México y Oaxaca.

9 Es difícil obtener datos oficiales de exportación, ya que este grano carece de posición arancelaria propia, siendo clasificado en un rubro como "otros cereales». A nivel mundial los consumidores de amaranto han aumentado en China, India, Japón, Alemania, Eslovaquia, Polonia y Kenia entre otros (http://www.amaranto.org.mx. Consultado el 05/07/17).

10 En la periferia de Ciudad de México persiste el pueblo de Tulyehualco, en Delegación Xochimilco, que está bastante urbanizado, pero con áreas de siembra y que también tiene una fuerte tradición en la producción de Alegrías y otros dulces tradicionales. 
en tierras ejidales tanto agricultura de autoconsumo (maíz, frijol y calabaza), como productos con fines comerciales (caña, hortalizas, sorgo y otros).

No obstante, la elaboración de dulces y derivados de amaranto constituye la principal actividad de estos pueblos y es medio de sustento para muchas familias en Temoac. Su importancia se deduce rápidamente del hecho que, mientras la producción estatal de amaranto es menor a 300 toneladas, el conjunto de talleres y empresas en Morelos requiere alrededor de tres mil toneladas anuales. El déficit de materia prima tiene que ser adquirido en los estados vecinos que, como se mencionó previamente, se encuentran en la misma región del Altiplano Central. Antes de introducir otros elementos respecto a la importancia estratégica de este intercambio interregional, es conveniente conocer el perfil general de los llamados talleres y empresas familiares.

\section{Artesanos y agroindustrias rurales en Huazulco}

Se estima que en Temoac son más de cien unidades transformadoras, localizadas en las comunidades de Huazulco y en menor medida en Amilcingo. Se desconoce su número exacto, en buena medida porque muchos son talleres familiares y operan en sus propios domicilios, sin registro formal sujeto a régimen fiscal. ${ }^{11}$ Una minoría de estas micro o pequeńas agroindustrias alimentarias, ${ }^{12}$ se abastecen de la semilla de sus propias parcelas, pero la generalidad solo la adquieren de productores locales o intermediarios que lo compran en Puebla o Tlaxcala.

La gran mayoría de las micro y pequeńas empresas familiares se pueden caracterizar como Agroindustrias Rurales (AIR), definidas como aquellas unidades que realizan actividades «que permiten aumentar y retener, en las zonas rurales, el valor agregado de la producción de las economías campesinas, a través de

11 En México el Servicio de Administración Tributaria (SAT) hace una campańa permanente de incorporación fiscal para todos los negocios $y$, en especial, a los pequeños que suelen considerarse causantes de la economía informal. El SAT es un órgano descentralizado de la Secretaría de Hacienda y Crédito Público (SHCP), institución gubernamental encargada de manejar todo lo relacionado con ingresos y egresos del país.

12 De acuerdo a especialistas de la $\mathrm{FAO}$, la micro y pequeña agroindustria alimentaria se caracterizan por uso preferente de recursos locales, bajas inversiones, uso de tecnología simple o sencilla y potencialmente autosustentables. Se destaca su papel en países de América Latina y El Caribe, como fuente de empleos y de beneficio económico para los pequeños agricultores y población rural en las regiones marginadas. la ejecución de tareas de poscosecha en los productos provenientes de explotaciones silvo-agropecuarias» (Boucher, 2006: 5). ${ }^{13}$

$\mathrm{Su}$ principal rasgo organizativo está dado por el carácter doméstico de la producción, basado en la mano de obra familiar, y donde el jefe de familia suele tener el liderazgo, asignando tareas, comprando insumos y administrando el negocio para mantener el funcionamiento de la AIR y cubrir las necesidades del hogar. Las labores domésticas y en el taller se distribuyen entre sus miembros con base a su edad, sexo y responsabilidades en el patrimonio ocupacional.

Los talleres dulceros son también una fuente de trabajo para parientes y amigos, en particular para jóvenes adolescentes de ambos sexos y mujeres adultas del pueblo o comunidades vecinas que buscan empleo eventual como ayudantes complementarios (Moctezuma, 2008). Los altibajos en la demanda y otros factores específicos que influyen en que la producción se concentre en ciertas temporadas, así como la demanda de tareas simples (por ejemplo, envolver los dulces), hace que los talleres requieran emplear en distintos momentos y cantidades a esta mano de obra no calificada, a la que pagan por destajo y que puede ser solo por semanas o días; este tipo de empleo eventual con frecuencia se concentra por las tardes, pues los jóvenes van a la escuela por las mañanas y las mujeres realizan quehaceres domésticos. Demanda $y$ oferta se adecuan a un peculiar funcionamiento en el que es común la rotación de personas entre talleres; por su parte, las AIR procuran mantener buenas relaciones con familiares y amigos (o no tener mala imagen como empleadores), pues esta mano de obra complementaria es indispensable para asegurar su funcionamiento y crítica cuando deban cumplir pedidos extraordinarios. Algunas AIR emplean además trabajadores especializados en el proceso de fabricación de dulces, su ingreso depende de su experiencia y de la relación de parentesco con el dueño (ídem).

Los responsables de las AIR, los «maestros dulceros", conservan los saberes ancestrales, que se han transmitido por generaciones, y aún, elaboran sus productos de manera artesanal o con tecnología simple que facilitan sus actividades. Pero también algunos de ellos se destacan por crear nuevas recetas y buscar innovaciones permanentes que rápidamente

13 Estas tareas pueden ser la selección, el lavado, el almacenamiento, la conservación, la transformación, el empaque, el transporte y la comercialización de sus bienes (Boucher, 2006). 
son copiadas por otras AIR de la localidad. El oficio de dulcero no solo es visto como un patrimonio individual, sino que representa económica y culturalmente, un espacio familiar y colectivo en esta comunidad, considerada adicionalmente por los hogares del pueblo y otros cercanos, como una fuente de empleo que ayuda a obtener ingresos suplementarios.

En contraste a estas modestas unidades económicas de notable dinamismo, se encuentran las medianas empresas que operan en Morelos, una de ellas en el mismo pueblo de Huazulco, la otra en otro municipio al sur del Estado (Zacatepec). Las medianas agroindustrias han emanado de pequeñas empresas familiares que se fueron capitalizando, accediendo a créditos y otros recursos, lo cual les ha permitido adquirir tecnología e infraestructura industriales. En estas, la mayoría de sus trabajadores son asalariados y los puestos gerenciales son ocupados por miembros de la familia de origen. También se observa la automatización de las tareas, líneas de ensamblaje y moderno empacado, incorporando una mayor división de trabajo. A la vez que aumenta la productividad, se trata de disminuir en lo posible el contacto directo entre el producto y el trabajo manual, así como eliminar los utensilios y materiales de madera, en el cumplimiento de normas y estandarización del proceso. Las medianas empresas sí están formalmente registradas y certificadas por diferentes instancias, cuentan con páginas web para promocionarse, solicitar pedidos y medio de compra en línea.

Considerando el número de trabajadores regulares, en la investigación que sirve de base a este artículo, se utilizó la tipología para empresas del sector agropecuario, ${ }^{14}$ la cual clasifica como «micro» a aquellas que contaban de 1 a 5 personas, "pequeña» a las que laboran de 6 a 20 personas (en realidad, en Huazulco no superan la decena de trabajadores) y, finalmente, las «medianas empresas» de 21 a 100. Es evidente que la subcontratación y rotación de personal en las AIR que se ha mencionado previamente, no es fácil de captar bajo este esquema, sin embargo, sirve para tener cierta tipología de referencia que permite hacer otras observaciones sobre su comportamiento.

14 Se consideró la clasificación de las empresas del sector agropecuario en México, realizada por el Instituto Nacional de Geografía y Estadística (INEGI). Además de los rangos señalados, en esa clasificación se considera "gran empresa» agropecuaria la que emplea 101 trabajadores o más (Navarrete, 2016: 69).
Por otro lado, de acuerdo a su producción, las AIR se pueden dividir en especializadas y diversificadas. El primer tipo, que corresponde a las micro AIR, elaboran uno o dos productos, dando prioridad a lo que mejor saben hacer. La compra de insumos, equipos y herramientas necesarios se simplifica en esta especialización. El segundo tipo, las pequeñas AIR y medianas empresas tienen una producción diversificada, que consiste en desarrollar tres o más tipos de productos, así como sus variedades; por ejemplo, elaboran un producto con diferentes presentaciones y combinaciones.

Son múltiples los productos elaborados con amaranto, sea su ingrediente principal o como acompañante. Los lugareños los dividen por su sabor en dulces, salados, picantes y naturales. Junto a la Alegría tradicional con piloncillo (chancaca), adornada de uva pasa o nuez, se han multiplicado las variedades de golosinas, algunas de ellas con base en añadir otros sabores artificiales a la semilla de amaranto (chocolate, fresa, nuez y menta), y otras variedades que mantienen como base la Alegría tradicional, pero con nuevos ingredientes no tradicionales, como el arándano. Otra serie de productos se han obtenido de la fabricación de harina de amaranto, el cual ha sido base para elaborar atoles $^{15}$, galletas, obleas y frituras, entre otras aplicaciones. Como un ingrediente secundario, el amaranto se ha incorporado a la palanqueta de cacahuate (maní) o a productos modernos como las granolas. Los diversos productos se elaboran a lo largo del año en distintos montos, habiendo presentaciones que se adecuan a las fechas especiales, por ejemplo, para las celebraciones del Día de Difuntos se elaboran calaveras de amaranto, pues como es sabido en México existe toda una tradición al respecto, donde los «altares de muertos» se adornan con flores, frutas y ofrendas diversas, entre las que es común los dulces tradicionales. En menor medida, unas cuantas AIR y medianas elaboran nuevos productos acordes a una demanda más sofisticada que busca granolas, barras energéticas para deportistas, uso de miel de agave (en vez de miel de abeja) y otros específicos para diabéticos o celíacos (el amaranto no contiene gluten).

En suma, acorde a su tamaño y grado de tecnificación, las AIR han tenido la capacidad de

15 Bebida que convencionalmente se elabora con maíz cocido, molido, diluido en agua o leche y hervido hasta darle cierta consistencia; es típica de México y de otras zonas de América Central. En México también se hace de arroz y muy recientemente, de amaranto. 
adaptación a la expansión de la demanda, a través de estrategias particulares, como en la innovación en sus productos y diversificación de los mismos, pero también potenciando relaciones sociales y comerciales en un territorio extralocal, permitiéndoles ser competitivos en ciertos canales mercantiles modernos y el mejoramiento (upgrading) para mantenerse vigentes.

Además, cabe mencionar que la actividad de las AIR y mediana empresa generan la demanda de otros talleres y empresas que producen bienes intermedios o comercializan diferentes ingredientes que los transformadores requieren. Por ejemplo, son comunes las industrias caseras de obleas (láminas delgadas de harina de trigo) que se emplean en diversos dulces con ingredientes varios, las cuales suelen emplear mano de obra femenina (Moctezuma, 2008). O bien los que solo se dedican a «reventar» el amaranto de manera rústica o con modernas máquinas que usan gas para ello. ${ }^{16}$ De tal manera que en pueblos como Huazulco encontramos un conjunto heterogéneo de actores y múltiples unidades productivas de tamaño variable, sustentadas en campesinos productores de semilla, talleres familiares y pequeñas empresas cuyas actividades crean la presencia de otras que representan una importante fuente de empleo local y regional.

En cuanto a su tecnología, esta es artesanal en las micro AIR y mixta en las pequeñas AIR más modernas. Sobre todo las primeras, utilizan procesos tradicionales escasamente mecanizados, tales como mesa de trabajo y herramientas de madera ${ }^{17}$, uso de leña o mechero a gas, cazuelas de cobre o acero inoxidable y el sistema de empacado es la envoltura de celofán o plástico de los productos con uso de calor de plancha casera o una empacadora mecánica individual. Algunas más capitalizadas emplean revolvedora (aspas) eléctrica o un recipiente de acero inoxidable con aspas incluidas, reduciendo el esfuerzo y aumentando su capacidad productiva. En el caso de la mediana agroindustria ya no se usa el cazo, ni la revolvedora, se utiliza el equipo llamado «bombo", en el cual se realiza el calentamiento de los ingredientes y en este mismo se hace la

16 En Huazulco, la actividad del reventado de la semilla de amaranto puede ser alguien que también la produce, o solo compra la semilla para su posterior comercialización y se especializa en ello. Las máquinas reventadoras hechas por una empresa mexicana, San Miguel de Proyectos Agropecuarios SPR de RL, son de diferente capacidad, desde $25 \mathrm{~kg} /$ hora hasta $200 \mathrm{Kg} /$ hora

17 Herramientas auxiliares en el proceso de manufactura son: rodillos, reglas, moldes rectangulares grandes $(1 \mathrm{~m} \mathrm{X} 50 \mathrm{~cm})$ y moldes de piezas individuales, cuchillos, entre otros. mezcla; asimismo, como se señaló, emplean bandas transportadoras y otros desarrollos tecnológicos.

Cabe notar que en algunas pequeñas AIR se observó la sustitución de los materiales de madera a acero inoxidable o de plástico con el fin de cumplir con la normativa de calidad e inocuidad que exigen los programas gubernamentales, con la intención de acceder a modernos canales mercantiles.

De acuerdo a su dimensión y tecnología, las AIR utilizan un cuarto como taller dentro de su casa, el traspatio u otros espacios adyacentes de tamaño variable, dependiendo de sus necesidades de producción y cantidad de personal. Las AIR usan directamente la materia prima e insumos en el proceso, es decir, no cuentan con un área de almacenamiento para ello, mientras en el caso de la mediana agroindustria, tiene su propia área de recepción, donde se supervisa la materia prima y si cumple con los requisitos de calidad que pide la misma empresa, pasa al área de almacenamiento, donde estará disponible.

Como se desprende de lo expuesto hasta ahora, las AIR tienen dificultades para cumplir con los estándares de industrias modernas de alimentos, instalaciones adecuadas y otros requisitos que les impide acceder a una certificación, a créditos bancarios o programas de subsidios. Desanima a estos artesanos el aumento de costos que implicaría modificar su organización, infraestructura y manera en que acostumbran gestionar recursos humanos y materiales. En última instancia, los trabas y resistencias que en general las AIR presentan, no reflejan incapacidad para un buen funcionamiento, más bien, son estrategias familiares de los sectores artesanales con medios limitados y, como tales, tienen como recurso fundamental su propia mano de obra y como meta principal garantizar el mantenimiento de su hogar y el bienestar de sus integrantes, pero también se sustentan en un significativo capital social de las comunidades rurales involucradas de Morelos y más allá. Para Patricia Moctezuma (2008: 9),la prevalencia de los talleres familiares en particular, expresa la valoración cultural del trabajo entre los dulceros y su prestigio regional, a pesar de lo atrayentes que pudieran ser otras modalidades organizativas, en términos comerciales y productivos.

Además, paradójicamente, estos obstáculos no necesariamente impiden que éstas agroindustrias artesanales participen en ciertos canales de comercialización, como se profundiza más adelante. 
En efecto, en cuanto a la distribución, en primer término, se puede destacar que las medianas agroindustrias y algunas pequeñas AIR tienen tiendas en las que venden directamente al menudeo y mayoreo, generalmente adosadas a la casa o al taller.En éstas se observa un aspecto común: no solo venden su propia producción, sino también productos de otras AIR lugareńase incluso de otros estados para ampliar su oferta de "dulces regionales», en cantidad y variedad que depende de sus relaciones y presupuesto. Junto a las típicas alegrías, palanquetas y derivados de amaranto de factura local, se pueden encontrar jamoncillos de leche, ates de membrillo, obleas con dulce de leche, frutas cristalizadas y otros dulces tradicionales mexicanos, sobre todo del vecino estado de Puebla. Las intenciones son evidentes: hacer las dulcerías atractivas al consumidor regional y al turista, pero también promover que intermediarios comerciales encuentren variedad y prefieran comprar en un solo establecimiento su mercancía al mayoreo. Curiosamente casi todas tienen la misma lógica comercialpues,aunque el volumen y diversidad de productos varíe de una a otra, procuran satisfacer todos los gustos comunes y algunas novedades para probar su demanda potencial.

Estas prácticas no se consideran desleales entre las AIR, sino más bien como formas complementarias entre empresas especializadas y diversificadas, las cuales se refuerzan a través de relaciones informales, o acuerdos de palabra basados en la confianza entretejida a través del tiempo, como parte de la cultura local y regional. La forma de pago entre los transformadores en su mayoría es en efectivo, pero no necesariamente inmediato y hay cierta flexibilidad en los plazos; su incumplimiento, merma la confianza y rompe los lazos en sus actividades comerciales, dificultando futuros tratos.

En segundo lugar, hay quienes solo comercializan por pedido y no venden directamente al público desde su nave de producción y tampoco tienen dulcería; en una de las AIR entrevistada, esta decisión se vincula claramente con su orientación a nichos de mercado de tiendas naturistas a las que envía su mercadería.

Por otro lado, tengan o no dulcerías propias, muchas de las agroindustrias en Huazulco, abastecen a las dulcerías locales o regionales, ya sea por medio de trato directo a pequeños comerciantes que venden en ferias itineranteso por medio de intermediarios comerciales.
Los intermediarios pueden ser personas de la misma localidad, familiares, amigos, o bien sujetos y empresas comerciales especializadas que introducen los productos al mercado regional, estatal y nacional. Estos intermediaros son los principales clientes para algunas AIR, pues teniendo asegurada la venta por pedido, algunos informantes manifestaron no tener la necesidad de asistir a ferias o eventos para ofrecer sus productos.

Minoristas y mayoristas, comercializan los productos de manera informal o formal, de acuerdo al mercado que va dirigido. Los minoristas, pueden abastecer pequeños negocios que complementan su economía familiar, como puestos en mercados de distinto tipo (artesanal, orgánico, popular), ferias (fiestas patronales) y pequeños establecimientos comerciales (misceláneas, tiendas naturistas, locales en escuelas). Los intermediarios mayoristas aprovisionan a comerciantes de la Central de Abastos de la Ciudad de México y distribuyen Alegrías a sistemas informales de venta ambulante en varias ciudades del centro del país. Pero también hay intermediarios que abastecena supermercados, tiendas departamentales y de conveniencia; en tales casos el intermediario adecua el producto a las exigencias del establecimiento, como colocarles etiquetas $^{18}$, código de barras, generar factura y certificaciones.

Empleando la misma estrategia comercial, también otro cliente importante para las AIR de Huazulco son otras agroindustrias más modernizadas en Tulyehualco, Ciudad de México, que adquieren el producto y le colocan su propia etiqueta, con lo cual cubren su demanda y mantienen su fama como grandes productores y dulceros.

Esta peculiar «maquila» de productos elaborados en empresas «informales» que luego acceden a mercados "formales» por medio del empacado, no es desconocidapara muchas AIR morelenses, de acuerdo a los hallazgos de Elizabeth Navarrete. Es, de alguna manera, el costo que deben pagar por no poder o no querer cumplir con los requisitos, licencias y permisos para operar como pequeña empresa elaboradora de alimentos, además de aquellos tributarios para poder emitir facturas.

18 En cada país las normas de etiquetado varían de acuerdo a las especificaciones de las legislaciones locales. En México la norma oficial mexicana NOM 051 es la base para realizar el etiquetado para alimentos. 
De acuerdo al estudio realizado, el comportamiento de las AIR en Huazulco se inscribe en un conjunto de relaciones e intercambios en que participan diversos agentes y comunidades del Altiplano Central que se encuentran en el territorio tradicional del amaranto: Puebla, Tlaxcala, Ciudad de México, Estado de México y Morelos. El caso de Huazulco en Morelos ilustra esta situación ya que sus talleres agroindustriales, necesitan abastecerse de amaranto producido en comunidades de Puebla y Tlaxcala, debido a que la siembra local de semilla no es suficiente. Luego de transformar la semilla del amaranto, Huazulco la regresa convertido ya en mercancías terminadas a las entidades proveedoras $\mathrm{u}$ otras, multiplicando así sus canales de comercialización. En el caso particular de Tulyehualco, si bien tiene su propia elaboración de dulces tradicionales y derivados de amaranto, no excluye que compren más productos de calidad a Huazulco (sin etiqueta), para su ulterior reventa bajo nuevos empaques. De aquí se desprende que, a nuestro juicio, se trata de un territorio integrado y no solo transacciones aisladas de amaranto ohuaubtli.

\section{Consumidor tradicional y nuevos consumidores}

Denominamos consumidor tradicional de amarantoa aquel individuo que consume el dulce convencional Alegría, en sus presentaciones más comunes y sin etiquetas que aludan a sus propiedades nutritivas o artesanales, pueden ser incluso sin envoltura, aunque ya se ha ido generalizando el uso de un celofán simple. ${ }^{19} \mathrm{El}$ valor ceremonial que tiene en algunas comunidades indígenas, refleja la persistencia del alto valor simbólico que tuvo en la cosmovisión mesoamericana, pero está fuera de los circuitos comerciales.

En tanto, el consumidor tradicional acude amercados fijosy rotativos, ferias y eventos anuales en Morelos o pueblos adyacentes del Estado de México, que se realizan principalmente por motivo del calendario festivo religioso popular (fiestas patronales y otras), encuentros artesanales, celebraciones ancestrales como Día de Muertos y mercados turísticos. Muchos de los comercializadores buscan a estos consumidores tradicionales, lo cual no solo se observa en sus presentaciones y tipo de productos, sino también en

19 Como se mencionó, el sabor y consistencia de la ancestral Alegríaes con base de miel y piloncillo (piloncillo), ingredientes que algunas agroindustrias en Morelos y otros diferentes estados han reemplazado por jarabe de azúcar como edulcorante, para reducir costos. la planificación de su producción anual y temporal. Otro mercado informal lo representan los peatones en zonas de mayor concurrencia o los automovilistas en los semáforos, quienes son fieles consumidores que compran a vendedores ambulantes de Alegrías de bajo costo ("tres-por-diez») en las ciudades de Morelos y México.

En general, en Huazulco la producción de las AIR se orienta mayormente a satisfacer a este consumidor tradicional. Le sigue en importancia, un conjunto de productos que cuentan con mayor valor agregado: sea porque contienen más ingredientes (alegrías con maní u otras semillas), sabores, combinaciones y presentaciones, o bien porque sin tener modernos empaques ni registro formal(código de barras), presentan alguna etiqueta simple que indica origen, reivindicando el prestigio del lugar. Este segundo nivel en que se diversifica e innova la producción dulcera de Huazulco, responde como veremos, a la modesta búsqueda de un nuevo mercado con mayor capacidad adquisitiva, pero que se ubica en espacios donde se mezcla lo formal e informal como, por ejemplo, puestos semifijos en universidades públicas y ferias artesanales, mercados turísticos y otros.

En el extremo opuesto, como ya mencionamos, se identificó una pequeña ymediana empresas en Huazulco que producen para un nicho de mercado distinto a los anteriores, en el que los consumidores buscan ingredientes orgánicos, sin saborizantes artificiales, las cuales están registradas por el Estado y cumplen con las normas oficiales de productos alimenticios. La otra empresa mediana, localizada en otro municipio, también tiene un perfil diferente a los talleres artesanales, en la que los mazapanes y otros bienes con base en amaranto son solo una línea de sus productos, siendo su principal materia prima el maní (importado y de patente de Estados Unidos), con el cual elaboran variedad de botanas y barras nutritivas.

Estas últimas empresas representan claramente los nuevos consumidores a que nos referimos al principio y que se asocian a preferencias del consumo alimentario que giran en torno a temas de salud, lo natural y lo ecológico. Si bien no se trata de nuevas tendencias pues ya se manifestaron desde los ańos setenta ${ }^{20}$, lo cierto

20 Nos referimos al hecho de que, tras el desencanto de la modernización y en respuesta a estas externalidades negativas de la industrialización agroalimentaria y el deterioro ambiental, surgen una serie de tendencias opuestas, que revalorizan la artesanía alimentaria, que la relacionan más con lo rural que con lo urbano (Espeitx 1996). 
es que parece haber un constantedescubrimiento y redescubrimiento de ventajas o beneficios de distintos alimentos saludables, nutracéuticos y energizantes, como el amaranto.

Aunado a ello, sigue siendo un atractivo para ciertos consumidores que los alimentossean "artesanales», en oposición a la excesiva tecnificación de la industria alimentaria. Así, al amaranto le ha llegado su gran momento de popularidad, desde hace unos años, cuando progresivamente no solo se han integrado versiones sofisticadas y distintas de los dulces tradicionales en cadenas de supermercado, tiendas naturistas y otras gourmet, sino también han aparecido en los anaqueles de tiendas de autoservicio varios productos industrializados que contienen amaranto, anunciando en sus etiquetas este nuevo y valioso ingrediente en sus cereales o granolas. ${ }^{21}$

Nadie duda de las cualidades nutritivas del amaranto, sin embargo, lo que interesa es reflexionar sobre estos nuevos usos sociales que afectan bienes agroalimentarios como éste, de origen tradicional y artesanal. Con esta preocupación, se puede formular dos interrogantes relacionadas, por un lado, ¿cómo entender esta renovación del alto valor simbólico del huauhtli? y, por otro, ¿hasta qué punto este fenómeno beneficia a los productores y las AIR?

Antes de responder estas preguntas, viene al caso hacer referencia a un interesante estudio sobre la quinua en Perú (Ramírez Miranda et al., 2016), publicado recientemente por la revista Investigaciones Sociales. Los autores se preguntan justamente cómo beneficia a productores y consumidores el aumento de oferta y demanda de la quinua en este país. De acuerdo a las investigaciones realizadas en las zonas productoras de quinua en el Perú, en sectores que consumen en zonas rurales y urbanas, así como su destino en el mercado exterior, los investigadores concluyen que los campesinos enfrentan inclusión como productores y exclusión como consumidores. Los autores encuentran que, si bien la producción puede favorecer económicamente a la agricultura familiar en regiones andinas, es muy insuficiente el apoyo para integrar su consumo y realmente aprovechar su alto potencial nutritivo para la misma población que la produce; adicionalmente fundamentan la necesidad de fomentar su consumo en la población

21 La multinacional Kellogg's presenta ahora una «Granola granos ancestrales» con ¡quinoa y amaranto! en general en el Perú. En contraste, se señala que en los últimos veinte ańos hay un notorio incremento de las exportaciones y su principal destino son países como Estados Unidos, Alemania, Francia y Holanda, lugares donde se ha incorporado a la dieta como un ingrediente sano y sofisticado; es decir, países que sí se han incluido como consumidores. Por todo ello, los investigadores concluyen que la quinua tiene un gran potencial a favor de la seguridad alimentaria en Perú, objetivo más importante aún, aunque no excluyente, que su beneficio económico para la agricultura familiar; asimismo consideran que se debe fomentar la producción agroindustrial con políticas públicas que procuren el desarrollo sustentable y la inclusión social de la población (ídem: 245).

Por razones de espacio no ahondaremos en los planteamientos expresados, no obstante, es de destacar la similitud de tendencias que llevan a que bienes agroalimentarios, de arraigado origen en sistemas tradicionales de producción campesinay variados hábitos alimenticios en gastronomías vernáculas, no solo ha generado gran interés en empresas agroindustriales nacionales e internacionales al identificar su alto valor nutritivo, sino que además se apropian simbólicamente de imaginarios asociados a su identidad étnica y a la sabiduría ancestral que evocan, como valor adicional que pueden pagar modernos y sofisticados consumidores.

Retomando el estudio sobre el amaranto en particular, se considera que, para explicar cabalmente oportunidades y desafíos, se debe tomar en cuenta el contexto más ampliode transformaciones sociales que acompañan a una nueva etapa de globalización agroalimentaria que permea toda sociedad, que no se restringe a las grandes metrópolis y que, heterogéneamente, se hace sentir en diferentes latitudes. De acuerdo con William Friedland (1994 en Pedreño y Quaranta, 2010:10)la construcción de una nueva norma social de consumo y de producción de alimentos en la era global tieneentre sus principales atributos un incremento de la variedad y diferenciación del producto que incrementa las opciones de elección y la fragmentación del mercado en un gran número de segmentos.Tal libertad de elección, está inmersa en la lógica del mercado y, por ende, busca el consumismo, aunque el consumidor lo asuma como virtud del paradigma actual.

Sin embargo, estos rasgos no desplazan la norma previa —del periodo fordista-, que se asocia ala homogeneización del consumo, sino que actualmente 
se plasman en la existencia de un mercado masivo para los consumidores menos privilegiados.A la vez, un mercado segmentado, que pondera los valores de diferenciación y calidad, permite la proliferación de nichos de demanda que son altamente valorizados y para sectores de altos ingresos. En estos espacios es donde justamente adquieren especial relevancia aquellos alimentos o tradiciones culinarias que parecieran representan la antítesis de la mercancía homogeneizada, artificial y pobre de nutrientes e incluso dañinos para la salud. No se trata de un esquema lineal de cambios en los patrones alimentarios, ni la presencia de un modelo dicotómico de alimentación, sino más bien, de la combinación compleja de lógicas de estandarización y de diferenciación. En tales circunstancias, no extraña que se presenten procesos híbridos donde se producen masivamente mercancías que ofertan nuevas normas y modas de consumo alimentario más selectivas(Pedreño y Quaranta, 2010).

La mercadotecnia se ha encargado de utilizar $\mathrm{y}$ reciclar tópicos que evocan imaginarios que son positivamente valorados para ciertos consumidores, ratificando la tesis de que el consumo se debe ver también como un proceso portador y generador de significados. Entonces, en casos como el que interesa, cobra especial relevancia un conjunto de valores polisémicos, tales como "artesanía», "natural», "valor nutritivo» o «ancestral», los cuales pueden estar relacionados, aunque cada uno encierra connotaciones específicas. Sin embargo, se debe tener claro que, orientados para satisfacer tales nichos, se trata de nuevos productos y nuevos consumidores (Espeitx, 1996). ${ }^{22}$ Es decir, en un extremo de la cadena, ya no se trata de la misma Alegría producida por un taller artesanal, sin etiqueta ni marca, como tampoco el consumidor finales un viandante que desea una golosina a módico precio.

Los nuevos productos son adaptados a nuevas demandas, por ejemplo, normas higiénicas, aspectos de su presentación, certificación de procesos productivos, entre otros, pero paradójicamente, se rechaza los alimentos industrializados y estandarizados. Los nuevos consumidores, con frecuencia, pertenecen a sectores sociales urbanos con mayor capacidad adquisitiva y

22 Para Espeitx (1996), el valor simbólico de los alimentos es fundamental para comprender, en este caso, la renovación y amplia aceptación de las artesanías alimentarias. Por razones de espacio no ahondaremos en la discusión sobre los sistemas de representaciones que enmarcan las preferencias alimentarias. receptivos de modelos de consumo identificados con el cuidado de la salud y el cuerpo, o bien con la búsqueda de productos portadores de significados asociados a "lo artesanal» (como "hecho a mano», «natural», «no contaminado», «tradicional»). La distancia geográfica, social y cultural del consumidor, puede estar en proporción inversa a su precio, también éste un símbolo de prestigio.

Para «salvar» esta brecha entre producción artesana y nuevas exigencias, en el mercado se encuentran alternativas híbridas, como lo ilustra el ejemplo ya mencionado de una conocida multinacional que fabrica cereales, donde el producto es de clara factura no-artesanal, pero gracias a la mercadotecnia se privilegia el valor tradicional de la materia prima, lo «ancestral» del amaranto ("exótico» para consumidores en otras latitudes). Otra propuesta está representada por empresas pequeña y medianas de Morelos que, como otras en el país, han desarrollado procesos productivos mixtos para mantener su prestigio artesanal y, a la vez, ofrecer garantías higiénicas al consumidor, con el atractivo adicional de incorporar ingredientes prestigiados o de moda en el cuidado de la salud y el cuerpo (como miel de maguey).

Por otro lado, algunos autores consideran que, en este tipo de nichos de mercado, se puede encontrar oportunidades para impedir que grandes empresas del sector agroalimentario se apropien del patrimonio cultural de la agroindustria local (Amaya y Aguilar, 2012). En ese sentido, se sostiene que lasmodalidades de certificación asociados con el anclaje territorial, pudieran permitir la patrimonialización de los usos, manejo y saberes locales, a la vez de hacer posible la innovación (ídem).

Abundando en esta discusión, Gerardo Torres (2012), considera que, no obstante, este tipo de productos artesanales enfrentan la presión de un modelo de demanda que tiene al consumidor como eje de la gobernanza alimentaria, lo cual puede ser agobiante para las AIR y conllevar efectos indeseados al tener que satisfacer «un consumo urbano masivo, pero con aspiraciones a la autenticidad, como símbolo de la distinción mediante la valorización de los productos con identidad territorial.» (Torres, 2012: 72). Con base en evidencia empírica de proyectos de sistemas agroalimentarios locales $^{23}$, el autor señala que este

23 El autor discute en particular sobre la gobernanza de los Sistemas Agroalimentarios Locales (SIAL). El SIAL se concibe como un sistema de producción, transformación industrial y de servicios agroalimentarios 
hecho puede provocar procesos de diferenciación, que debilitanel tejido comunitario al promover procesos de integración asimétrica.

Las tensiones derivadas de este tipo de procesos de diferenciación, pueden ser agudizadas por diferentes actores involucrados, al tomar decisiones basadas en evaluaciones parciales o no pertinentes. Este es un riesgo latente en Huazulco, donde las propuestas impulsadas por programas gubernamentales, líderes $\mathrm{y}$ autoridades locales incurren en querer imponer visiones equívocas sobre la naturaleza de los talleres artesanos y las medidas que a su juicio favorecenel desarrollo.

En todo caso, la dulcería tradicional de Huazulco es cada vez más recurrida como componente central de la oferta turística y de la apropiación simbólica de esta tradición gastronómica local por parte de organismos públicos y privados externos. Este interés conlleva el efecto contradictorio de querer mantener los talleres artesanales y, a la vez, promover su conversión en modelos empresariales, considerando que su forma rústica de trabajo y su informalidad, restan eficiencia y competitividad.

\section{Conclusiones}

En este artículo se ha presentado una síntesis de una investigación sobre la cadena agroalimentaria de amaranto en el pueblo de Huazulco, Morelos - en el centro de México- en particular del eslabón compuesto principalmente por las agroindustrias rurales (AIR).A la luz de sus hallazgos se han dado argumentos que complementan y refuerzan las apreciaciones de este estudio de caso, las cuales difieren en lo central de enfoques que consideran necesario modificar y tecnificar a los productores y talleres tradicionales para mejorar su competitividad, en el supuesto de que ello traería mayor beneficio para estos actores y sus familias.

La evidencia empírica constata que en Huazulco, las AIR representan el núcleo más dinámico de la actividad en este poblado,que está conformado por cerca de un centenar de empresas de tamaño variable

con características territoriales específicas y de autogestión. No se trata aquí de hacer una exposición y debate sobre este enfoque, más bien se rescata una de las paradojas que Gerardo Torres identifica en los SIAL y que se considera pertinente para el caso estudiado de la artesanía alimentaria de amaranto. y en donde predomina el taller familiar; también en menor proporción, pero con presencia significativa en el mercado formal, existe en Morelos la mediana agroindustria de amaranto.

Las agroindustrias en Morelos requieren de otras entidades productoras de semilla de amaranto, como estrategia a la limitada producción local, peroa su vez, surten de productos intermedios y finales a otras comunidades vecinas y canales mercantiles nacionales. El análisis de las estrategias productivas y de comercialización, mostró que existe una red de relaciones e intercambios que hace interdependientes a comunidades amaranteras de Morelos, Puebla, Tlaxcala, Ciudad de México y Estado de México, que conforman un mismo territorio ancestral que rodean los volcanes Iztlacihuatl y Popocatepel. Esta cercanía geográfica y cultural les ha permitido conformar y mantener vínculos sociales, relaciones de reciprocidad y confianza, compromisos informales y formas flexibles de gestión, así como la complementariedad productiva y comercial entre las agroindustrias de diferentes tamaños, abasteciéndose mutuamente y respetando la especialización de cada una. Estas agroindustrias se mantienen en activa participación en el mercado global a pesar de que algunas no cuentan con una figura formal, entrando al mercado a través de intermediarios comerciales y abasteciendo desde el mercado tradicional y, en parte, anuevos consumidores.

Paradójicamente, el desarrollo del mercado segmentado y una nueva norma social de consumo ha representado cierto rescate y revalorización de la artesanía alimentaria, en particular de los dulces tradicionales.En países como México, este fenómeno ha influido en abrir, potencial o efectivamente, canales alternativos de comercialización para la pequeña y mediana empresa. No obstante, hay limitado acceso a las cadenas de supermercados y otros nichos de mercado (naturista, gourmet, etc.) y genera cierta diferenciación dentro de las propias agroindustrias.

La ampliación de demanda de productos de amarantoen este tipo de espacios, tiende a crear falsas expectativas de aprovechamiento por parte de las AIR más tradicionales, e incluso propiciar la búsqueda de financiamiento por organismos de gobierno y aceptar programas de reconversión técnica u organizativa que pueden atentar contra la cultura productiva y gastronómica local. Sobre todo, la creciente importancia de las cadenas de supermercados como 
canales de distribución de alimentos en México, así como la expectativa de ganancias en el mercado internacional —a juicio de las autoras-, puede llevar a que productores y AIR, apoyados $\mathrm{u}$ orientados por promotores públicos y centros de investigación, contemplen propuestas para incrementar las actividades que pongan en cuestión el desarrollo rural sustentable de la actividad y las comunidades implicadas.

Confirma este temor, la preocupación expresada por productores en un encuentro nacional, por la caída del precio de la semilla del amaranto, debido a la sobreproducción en Tlaxcala en el ciclo 2015 (récord de 4,797 hectáreas), lo que llevó a que varios productores de este estado y otros se desanimaran a sembrar el siguiente año, por los bajos precios de la semilla en el mercado (como se mencionó al inicio de este texto, ello significó una reducción de tres mil hectáreas). Las instituciones oficiales no tomaron medidas eficaces para amortiguar este descalabro y sucumbieron a las reglas del mercado.

Asimismo, y en referencia al estudio comentado al inicio de este artículo que diagnosticó que la cadena de valor estaba poco integrada y carente de vínculos horizontales, cuestionamos sus conclusiones para el caso morelense. El estudio desde Huazulco, por contrario,mostróque existen densasredes entre productores, transformadores e intermediarios que tienen alcance interregional, con añejas relaciones.

Sin duda, el auge de consumo ha influido en las decisiones de la dinámica de la cadena, incrementando el valor comercial de los productos de amaranto, para ello las AIR han aprendido a adaptarse en lo posible, a nuevas exigencias y mantener su perfil artesanal tradicional, más congruentes con sus valores y cultura.

\section{Referencias bibliográficas}

Amaya, Santiago y Encarnación Aguilar (2012). Saberes locales, tradición e innovación: el caso del Jamón Ibérico de Bellota. Nuevas tendencias en Antropología, 3, 109-136.

Ayala Garay, Alma Velia; Espitia Rangel, Eduardo; Rivas Valencia, Patricia; Martínez Trejo, Guillermina; Almaguer Vargas, Gustavo (2016). Análisis de la cadena del valor de amaranto en México. Agricultura, Sociedad y Desarrollo, 13 (1), 87-104.

Espeitx Bernat, Elena (1996). Los 'nuevos consumidores o las nuevas relaciones entre campo-ciudad a través de los "productos de la tierra", Agricultura y Sociedad, (80-81), 83-116.

Moctezuma, Patricia (2008). Dulces, mujeres y trabajo en Huazulco. Inventio. Universidad Autónoma de Morelos (UAEM), Morelos, 7(4), 7-13.

NavarRete Galindo, Elizabeth (2017). La ruta del Huaubtli (amaranto) en Morelos (Tesis de maestría). Universidad Autónoma del Estado de Morelos, Morelos.

Pedreño Cánovas, Andrés y Germán Quaranta (2002). Introducción. Trabajo y sociedad en los campos de la globalización agroalimentaria. Áreas, Revista de Ciencias Sociales, (2) 22, 9-26.

Ramírez Miranda, Durga, E. Ramírez Miranda y Luz Sáenz Arana (2016). Propiedades alimenticias de la quinua y sus paradojas de inclusión y exclusión social en el Perú (2011-2014). Investigaciones Sociales, 36, 231-245.

Torres Salcido, Gerardo (2012). La Gobernanza de los sistemas agroalimentarios locales. G. Torres Salcido y R. M. Larroa Torres (coords.), Los sistemas agroalimentarios localizados. Identidad territorial, construcción de capital social e instituciones, CEIICH-UNAM, México, 69-88.

Vargas, Luis Alberto y María de la Luz Del Valle (2016). El nuevo reventón del amaranto, Arqueología Mexicana, $138,58-63$. 